\title{
Contribution of Pathology in Surgical Oncology in Malignant Tumors of the Salivary Glands
}

\author{
IOAN SIRBU ${ }^{1}$, CRISTIAN CONSTANTIN BUDACU ${ }^{2}$, CONSTANTIN VOLOVAT ${ }^{3 *}$, VLAD DANILA $^{2 *}$, \\ OVIDIU MIHAIL STEFANESCU², MIHAELA MONICA SCUTARIU², \\ SIMONA RUXANDRA VOLOVAT ${ }^{3 *}$, VICTOR COSTAN ${ }^{2}$ \\ ${ }^{1}$ Carol Davila University of Medicine and Pharmacy, Faculty of Dental Medecine, 37 Dionisie Lupu Str., 020021, Bucharest, \\ Romania \\ ${ }^{2}$ Grigore T. Popa University of Medicine and Pharmacy, Faculty of Dental Medecine, 16 Universitatii Str., 700115, Iasi, \\ Romania \\ ${ }^{3}$ Grigore T. Popa University of Medicine and Pharmacy, Faculty of Medecine, 16 Universitatii Str., 700115, Iasi, Romania
}

The practice of oncology continues to be an area of continuous renewal. The volume of knowledge in the field of cancer therapy is increasing rapidly compared to any other medical discipline, constraining the need for permanent information. The first data on malignancies are linked to the $11^{\text {th }}$ century BC. The concerns of physicians were attracted to the cancerous disease, the observations and hypotheses regarding it being mentioned in different writings of the time. The increased frequency of cancer in the oro-maxillofacial region is favored by a number of factors: the great diversity of maxillofacial structures and the very important changes in the phylogenesis and ontogeny of these structures; the embryonic existence of the branchial arches, with the possibility of remaining residues in this stage; function of the intense quality of the face region and the oral region, as the first segment of the matter import apparatus; the multitude of irritant factors, which play an important role in the occurrence of cancer ( temperature, food hardness, dust, chemical noxiousness). The improvement of the methods and techniques of the surgical operations performed on the maxillofacial region had a decisive influence on the treatment of this region. In patients whose pathologic (bleeding diathesis, heart disease, liver disease, diabetes, etc.) can lead to various complications (local and general), interventions of oral and maxillofacial surgerycan perform as a preparation prior appropriate. The study includes a sample of 48 patients with malignant tumors of the salivary glands. The treatment of malignant tumors of the salivary gland have to be as wide early and surgically, with radiotherapy and / or multi-agent chemotherapy. Radiotherapy alone is insufficient, indicated only as palliative treatment.

Keywords: oncologia, pathology, surgery, chemotherapy, radiotherapy, salivary glands.

In order to understand the life of a sick organism, it is necessary to know the morphological changes in different stages of pathological processes development; the morphology deals with the study of the morphological changes in a sick organism. The cellular pathology was the first scientific theory that sought to explain the essence of the disease. The etyhiology of the pathological act is understood, both by the cause and the whole complex of conditions in the presence of which the pathogen manifests its action on the organism, causing the pathological process. Clarifying the mechanisms of appearance and development of the pathological processes and diseases is the task of the pathology. It is closely related with the etiology. In the pathology of the diseases the disorders of the correlations between the central nervous system and the internal environment of the organism occupy an important place. In the pathogenesis of diseases, disorders of trophic function of the nervous system are of a particular importance[1].

Disorders of saliva secretion can be quantitative and qualitative in nature. Quantitative modifications are of two types: decrease and increase of salivary secretion. Intensification of saliva secretion or hypersalivation occurs as a result of the excitation of the secretory nerves of the salivary glands. Sometimes, supersalivation occurs after bulbar paralysis, following localized bleeding at the bulb level. This phenomenon resembles the so called paralitic secretion of the saliva that is seen sectioning the tympanum cord. It can be assumed that, in bulbar paralysis, following paralysis of the swallowing center and the nuclei of the facial nerve, salivation really depends on the salivary swallowing disorder. Hypersalivation is also noticed as a result of reflex excitations of the secretory nerves (during pregnancy,

*email: constantin.volovat@umfiasi.ro; vlad.danila@umfiasi.ro; simona.volovat@umfiasi.ro 
vomiting, inflammation of the abdominal organs)[2]. Hypersalivation cannot be caused by inflammatory and localized processes in the oral cavity, as well as by a series of parasympathetic-mimmetic substances. The pathological hypersalivation influences the formation and wetting of the food bowl with mucus and at the stomach level of some rot and fermentation processes. The decrease in salivary secretion can occur as a result of reflex disorders of the function of the salivary glands, as well as due to the disturbance of the water metabolism. During the febrile processes, the salivary secretion is usually diminished, the reflex-conditioned salivary secretion being particularly low.The strong painful sensations, as well as the negative emotions, often cause changes in the function of the different segments of the gastrointestinal tract, in this case, the sensation of dryness in the mouth, the diminution of gastric juice secretion, and so on. The basis of all these changes is the disturbance of function of the central nervous system. The decrease of the salivary secretion is also found following the dehydration of the body due to profuse sweating, strong bleeding, prolonged diarrhea, as well as from the action of substances that paralyze the parasympathetic nerves[3].

The decrease in salivary secretion hinders the act of chewing and swallowing and contributes - as a result of the intense development of the bacterial flora - to the appearance of fermentation and putrefaction processes in the oral cavity. The hypersecretion can cause the retention in the body of certain metabolic products commonly eliminated by saliva, as well as some series of substances introduced besides mercury, lead, copper[4].

The reaction of saliva, which is usually weakly alkaline, may change in relation to the disorders of digestion and metabolism. Certain pathological processes, such as diabetes mellitus, fever, often cause the concentration of hydrogen ions in the saliva to increase, with deviation in the sense of acidosis. Changes in the composition and reaction of the saliva may also contribute to the appearance of dental caries. The salivary glands are part of the group of organs that possess a large number of vegetative nerves, through which the impulses from the central nervous system are transmitted; depending on the character of the salivary secretion in response to the action of the different conditioned excitators, the state of the reflex-conditioned activity can be appreciated.Pathological processes can also be seen in the tonsils; inflammatory processes of an infectious nature (angina) may occur in them. They prevent the act of swallowing and influence the secretory processes in the oral cavity. The tonsils apparatus represents the gateway for a series of infections[5]. At the level of the tonsils, the infectious process may persist for a long time, provoking from time to time repeated general reactions after germs enter in blood.The attention was drawn to the teeth (in the case of alveolar granulomas) and to the tonsils as possible outbreaks of latent infection, which extends from here on the whole body. This is the so-called outbreak infection[6].From these outbreaks the body can be invaded with toxins and various products of the biological activity of the infectious agents that sensitize the body, making it hypersensitive to the subsequent penetration of their substances into the general bloodstream. On this basis, an allergic condition develops, which is probably the cause of a series of diseases (rheumatism, septicemia, etc.). In addition, there is the possibility of reflex influences on the coronary vessels and the heart, starting from the damaged tonsils.From the oral cavity, the food enters the pharynx. The paralysis of the tongue - especially of bulbar origin - makes it difficult to penetrate the food into the pharynx and makes it impossible to use food in a solid state.

Malignant tumors of the salivary glands

Mucoepidermoid carcinoma is the most common malignant tumor of the salivary glands; the origin of the tumor is uncertain, probably in the reserve cells of the intra and interlobular ducts. It occurs more frequently in women and affects both major and minor salivary glands. It may also have intramandibular localization, possibly with a starting point in salivary glandular elements embedded during embryonic development, or by malignant mucosecreting cells in the wall of odontogenic cysts.

The clinical appearance varies depending on the aggressiveness: low-grade epidermoid carcinomas are similar to benign tumors.Microscopic evidence of the biphasic structure of the tumor: epidermoid and mucosecreting cells in variable proportions - the more the tumor has anaplasia degree, the smaller the mucosecreting cell population. The metastases do not respect the proportion of epidermoid cells: the mucosecreting cells in the primary tumor.Epidermal carcinomas with a low degree of anaplasia present numerous mucosecretory cells arranged in the microcystic structures as well as epidermoid cells without too many atypia; mucus lakes can appear that stretch and compress the tumor conjunctival stroma; sometimes mucus-filled cysts may rupture, leading to an important inflammatory response. Tumor margins more compress than invade normal surrounding tissues.

Medium or high grade anaplastic carcinomas contain beaches of epidermoid cells with significant pleomorphism and nuclear tachromacy; mucus lakes are extremely few or absent. The tumor infiltrates the surrounding tissues in the form of cords and trabeculae.

Immunohistochemical tumor cells are positive for neutral glycoproteins and acid sulfin-like mucin and sialomucine (mucosal cells) and cytokeratin (epidermoid cells).Cystic adenoid carcinoma most commonly affects the minor salivary glands (palate, antrum, tongue and nasal cavity are most commonly affected).Clinically, it appears as the tumor node is 
firm, painful, vaguely adherent to the underlying planes, the infiltration of the neighboring tissues is characteristic of this type of tumor; in time, the invasion of bone structures and the ulceration of the overlying tissues appear. Nervous invasion (usually the facial nerve or the auricular nerve) is the rule - sometimes facial paralysis occurs before the tumor node is discovered. The period from onset to diagnosis may include several years, in correlation with the slow clinical evolution of the tumor. The origin of the tumor appears to be represented by the cells in the intercalary terminal ducts[7].

Microscopically characteristic for cystic adenoid carcinoma is the tendency marked by intra- and perineural invasion, as well as the tendency towards the formation of pseudo-cystic spaces containing acellular substances. The presence of intravascular tumor emboli can be observed in a large number of cases., tumor cells are positive for lysozyme and amylase.

Carcinoma of the acinar cells mainly affects the major salivary glands. The origin of this neoplasm seems to be a reserve cell in the intercalary duct rather than the acinar cell itself.

Acinar cell carcinoma can affect any age group, from children to the elderly. There is no predilection for sex, but only a slight preference for women[8].

Clinically manifested by the presence of a single or multiple node, possibly bilateral, firm, painful, slow progressive; it can appear on ectopic salivary tissue. By section, the tumor node appears well delimited, brown, mixoid.The interval elapsed from the moment of appearance until the surgical exertion is variable - from a few months to a few years.

The microscopic finding shows a well encapsulated proliferation, usually without major cystic degeneration. The stroma is small, vascularized. Immunohistochemically, the cells are positive for cytokeratin, membrane epithelial antigen, antigencarcinoembryonic antigen, amylase, lactoferin, lysozyme.The malignant mixed tumor comprises several entities: the malignant mixed tumor, the carcino-sarcoma and the metastatic mixed tumor.

The malignant mixed tumor represents the variant with epithelial malignancy, usually derived from a pre-existing pleomorphic adenoma.

Carcinosarcoma (the true malignant mixed tumor) is the variant with epithelial and mesenchymal malignancy; tumor metastases include both epithelial and mesenchymal malignant elements.

In the salivary gland carcinoma, both carcinomatous and sarcomatous areas, most commonly chondrosarcoma, are present.

The cytologic appearance of the pleomorphic adenoma is characteristic of cases of mixed metastatic tumor, in which the diagnosis of malignancy is made when the presence of lymphoganglionic metastases of the primitive tumor is ascertained; however, the possibility of having a pleomorphic adenoma developed on the ectopic salivary tissue in the respective lymphoganglion should not be excluded.

Low-grade polymorphic adenocarcinoma occurs mainly in the minor salivary glands, especially in the palate. The origin of low-grade polymorphic adenocarcinoma is considered to be the proximal portion of the salivary ducts, probably in the reserve cells of the intercalated ducts.

It occurs in the elderly, without predilection for sex.It occurs in the form of firm, painless nodules, usually without ulceration of the overlying mucosa; the tumor growth is slow - sometimes it takes years until resection $[9,10]$.

Characteristic is the tendency marked by perineural invasion, but unlike the cystic adenoid carcinoma in which the nerve involvement usually involves large neural trunks, in the low-grade polymorphic adenocarcinoma small nerve branches are affected; similar concentric architectural aspects are evident in the vessel and in the neighborhood. Epimioepithelial carcinoma was first described in 1972 (Donath); with localization in the parotid gland; 10\% of cases affect the submandibular gland and 5\% the minor salivary glands.Clinically presents as a firm nodule, with slow growth, possibly with facial paralysis. The tumor is multinodular, encapsulated, but on microscopic examination there are areas of overgrowth of the capsule or its absence. Microscopic is the appearance of a clear cell tumor; two cellular populations can be identified, namely dark, cubic cells with positive PAS material resistant to intracytoplasmic diastasis, arranged around a lumen which also contains positive PAS material and clear, myoepithelial, oval or polyhedral cells, arranged around the preceding ones[11,12].

Salivary duct carcinoma occurs in men ( $80 \%$ of cases), in older age groups, predilection in the parotid gland in the form of a firm, painless tumor node; usually, the interval elapsed from the time of appearance until diagnosis is about one year.

Sebaceous adenocarcinoma of the salivary glands is an extremely rare tumor; clinically it presents as a 1-6 cm diameter node, painful, associated with facial paralysis. Microscopic tumor consists of a proliferation of pleomorphic cells having rich, clear, important cytoplasm nuclear atypia, anisocarries and nuclear hyperchromacy, arranged in compact beaches or in nests $[13,14]$.

Oncocitic carcinoma that is very rare and is mainly localized in theparotidian. The diagnoses criteria are represented by the presence of nuclear pleomorphism and mitotic oncocite too, perineural invasion, or the presence of perivascularperiparotidian tissue invasion and / or lymphatic determinations[15]. 
Malignant lymphoepithelial lesion (carcinoma undifferentiated by salivary gland with lymphoid stroma) - may occur in the context of the presence of a benign or novo lymphoepithelial lesion, without the possibility of identifying its characteristic elements.

Microscopically, the presence of epithelial islands with atypical and nuclear monstrosities, atypical mitoses; the islands and epithelial nests are surrounded by a diffuse infiltrate lymphoplasmocyte.

Small cell carcinoma (neuroendocrine carcinoma) was described in 1972; it is frequently located in the small salivary glands of the pharynx, larynx, paranasal sinuses, oral cavity and nasal cavities; it has neuroendocrine differentiation.

Microscopic it is composed of small cell beaches, with large nuclei, round-oval, hyperchromatic and neurosecretory granules in the cytoplasm; the neurosecretory granules can be detected either electron-microscopically or immunohistochemically. The presence of intravascular emboli and perineural invasion is regular[16].

Salivary lymphomas - The salivary glands may be the site of malignant lymphomas or different forms of Hodgkin's disease; their origin is represented by either the parotid or submandibular lymphoganglions or the extranodal salivary tissue, especially following a benign lymphoepithelial lesion.

Primitive salivary lymphomas are common at parotidian and submandibular levels; are generally non-HodgkinianHodgkin's disease very rarely affects the salivary glands.

Occasional progression of Sjogren's syndrome to malignant lymphoma, although rare, is known; in this case lymphoma is of type B. Rarely is the bilateral parotidia affected.

Salivary sarcomas - primitive salivary sarcomas are very rare; The association with the carcinomatous areas-the salivary carcinosarconum must always be sought. The parotid gland is most affected.Salivary tumor metastases are rare; the most common are epidermoid or malignant melanoma metastases from the region and clear cell renal metastases.

\section{Experimental part}

Material and method

For the name of salivary gland tumors there are a large number of terms which often cause confusion, and the classification of these tumors can be done according to various criteria: anatomical location, histological type, degree of malignancy.The study includes a sample of 48 cases with malignant tumors of the salivary glands.

\section{Result and discussions}

Salivary gland tumors are rare and develop in both the main and accessory salivary glands; most are located in the parotid glands, and in the case of the accessory salivary glands the most frequent site is the palatal tumors.

Any intra-parathyroid chronic formation whose nature could not be specified should be surgically explored and removed.

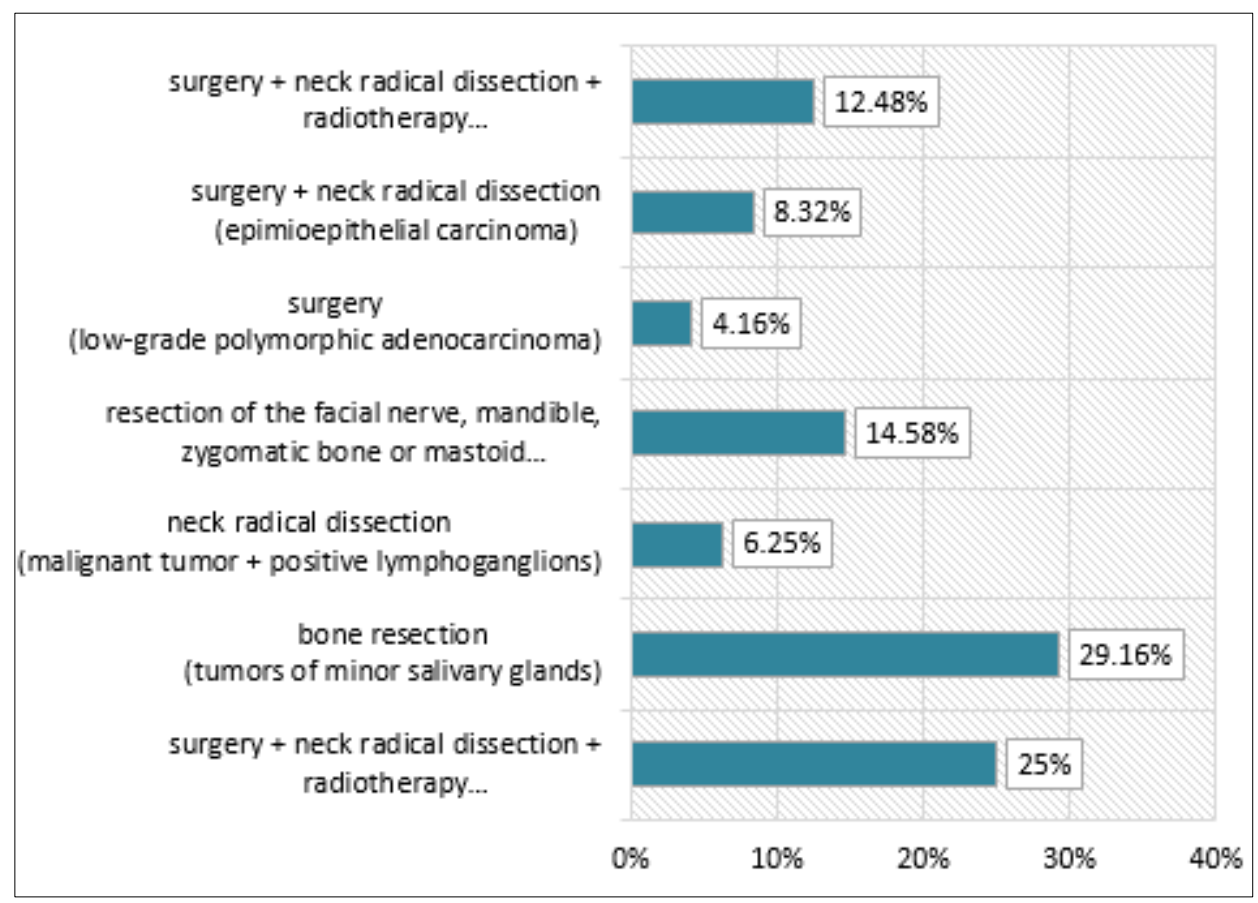

Fig.1 Distribution of surgical therapy 
The treatment is surgical in 12 cases $(25.00 \%)$ with tumors with high degree of anaplasia, it is recommended to perform radical neck dissection as well as postoperative radiotherapy. Subsequent evolution differs depending on the degree of anaplasia of the lesion: those with high degree of anaplasia it presents with local metastases and recurrences in the first 5 years after the resection of the primitive tumor in $60 \%$ of cases (Fig.1).

Radical resection of the tumor with preservation of the facial nerve, the treatment of choice is the surgical one, if it is not embedded or invaded by the tumor - in case of parotid localization and bone resection in the case of tumors of minor salivary glands - 14 cases $(29.16 \%)$

If the existence of positive lymphoganglions for the tumor is clinically suspected, radical neck dissection-3 cases $(6.25 \%)$ is indicated.

Postoperative radiotherapy is performed routinely. Cystic adenoid carcinoma invades the bone marrow spaces, which is why the tumor resection needs to be extended. The biological behavior of recurrent tumors is more aggressive than the first resected tumor.

The most common metastases are the pulmonary ones; once they appear they remain stable as evolution for a long time.

In the case of carcinoma of the acinar cells the treatment is surgical; recurrence is the rule, the tendency of metastasis, both to the regional lymphoganglions and to the distance is reduced. Among the unfavorable prognostic factors are: the pain, the local invasion, the incomplete surgical resection, the important desmoplastic reaction, the presence of numerous atypia or a mitotic index.

In the case of the mixed malignant tumor, the treatment consists of radical surgical resection. If the tumor is large and invasive it can be passed to the resection of the facial nerve, jaw, zygomatic bone or mastoid - 7 cases (14.58\%). If there are clinically suspected lymph nodes, neck dissection is practiced. In one third of cases, metastases occur at a distance usually in patients with local tumor recurrence.

Low-grade polymorphic adenocarcinoma, the treatment is surgical, favorable prognosis and it is not affected by the presence of perineural invasion-2 cases $(4.16 \%)$.

Epimioepithelial carcinoma, the treatment is surgical: tumor resection with a limit of comfortable oncologic security, possibly with neck dissection - 4 cases $(8.32 \%)$ Prognostic is favorable; frequent recurrences occur but rarely metastases.

In salivary duct carcinoma the treatment consists of surgical resection, neck dissection and postoperative radiotherapy. The biological evolution of the tumor is marked by the occurrence of multiple lung and bone metastases -6 cases (12.48\%).In sebaceous adenocarcinoma, treatment requires complete surgical resection associated with radiotherapy.

The malignant lymphoepithelial lesion has a very poor prognosis; it rapidly metastasizes to the regional lymphoganglions and death is usually.

Molecular biology research has revealed, as in the case of undifferentiated carcinoma of the cavum, the presence of Epstein-Barr virus in tumor cells.

\section{Conclusions}

Although in most patients lymphoepithelial lesions remain benign, in a small number of cases there is the possibility of malignant evolution, either on account of lymphoid tissue or of the epithelial component (lymphosarcoma) and also adenocarcinoma and anaplastic carcinoma.

\section{References}

1.MIRON, L., MARINCA, M.,Oncologie generală, ediția a II-a, Editura 'Grigore T.Popã Iași 2012.

2.De VITA, V.T. Jr., LAWRENCE, T.S., ROSENBERG, S.A., DEPINHO, R.A., WEINBERG, R.A., ed. De Vita, Hellman, and Rosenbergs Cancer -Principles and practice of oncology 9th edition, Philadelphia:Wolters Kluwer-Lippincott Williams Wilkins, 2011.

3.HLADNIK, L.H., WILLS, A.R., AUGUSTIN, K.M., Systemic chemotherapy:special considerations. In Govindan R, ed The Washington Manual of Oncology, 2nd edition, Philadelphia:Wolters Kluwer-Lippincott Williams Wilkins, 2008.

4.DY, G.K., AJEI, A.A., Principles of chemotherapy.In Chang AE, ed. Oncology-an evidence-based approach.NewYork:Springer, 2006:14-40.

5.CIURCANU, O., CIUPILAN, C., SAlCEANU, M., MELIAN, A., FORNA, DA., SCUTARIU, M.M ., Particularities of the dental treatment strategy in geriatric patients, RJOR, 2018 Volume: 10, 1, Pages: 108-113

6.EARAR, K., BICA, C., CERGHIZAN, D., et al.,The Role of Functional Polymers in the Optimization of the Acrylic Biomaterials Used in Removable Prosthetic Restoration III. Behaviour of the adhesive used for the multilayer consolidation, Mat.Plast. , 53, no.3, 2016, p. 512-517

7.SCUTARIU, M.M., MACOVEI, G., CIURCANU, O.E.L., SURDU, A., FORNA, N. C., Contributions to the characterization of biocenosis complex of the ecosystem in the oral cavity, The Medical-Surgical Journal, 2017, 121, vol. 4, pg. 801-805

8.SKEEL, R.T., KHLEIF, S.N., ed. Handbook of cancer chemotherapy 8 th edition, Philadelphia:Wolters Kluwer-Lippincott Williams Wilkins, 2011. 
9.MURARIU, A., FORNA, AGOP, D., MANOLACHE, F., et al.,Assessment of the oral health risk factors in young people, Romanian journal of oral rehabilitation , 9 ( 3) ,2017, Pg: 48-54 ;

10.SCUTARIU, M.M., DANILA, V., CIUPILAN, C., CIURCANU, O.E ., Semiology of the Pain Syndrome - Identifying the Ideal Methods of Locoregional Anesthesia Based on Their Rationale and Features; Rev. Chim.(Bucharest), 68, no. 10, 2017, p. 2373-2377

11.EARAR, K., GRADINARU, S., PARIZA, G., et al., Effect of the Sterilization Procedures of Different Surgical Meshes for Abdominal Surgery, Rev.Chim.(Bucharest), 68, no.8, 2017, p. 1868-1873

12.VASINCU, D., IANCU, R.I., CHELARU,L., STOLERIU,G., COSTULEANU, M., Biochemical effects of some endoplasmic reticulum stress inducers on mesenchymal stem cells in vitro,Rev.Chim.(Bucharest), 69, no.6, 2018, p.1570-1573

13.CIURCANU, O.E., FORNA, D.A., POPA, C., SCUTARIU, M.M., Implementation of methods of loco-regional anesthesia in dental surgery. RJOR, 2017 Volume: 9, 4, Pages: 120-127

14.LUPUSORU, R.V., TOPOR, G., MIRON, I.C., et al., Chemical Factors which Prompt Oral Pathological Phenomena In Some Nutrition Diseases, Rev. Chim.(Bucharest), 70, no.5, 2019, p.1884-1887

15.DASCALU, C.G., ANTOHE, M.E., GOLOVCENCU L., et al.,Interaction Schemes for the Analysis of Combined Action of Risk Factors,2017 IEEE International Conference on e-health and Bioengineering Conference (EHB) Book Series: E-Health and Bioengineering Conference, 2017, Pages: 462-465

16.TATARCIUC, D., VASINCU, D., STOLERIU, G., IANCU, R.I, COSTULEANU, M., Biochemical effects of Intraliposomal angiotensins on isolated vascular smooth muscle cells, Rev.Chim.(Bucharest), 69, no.5, 2018, p.1187-1190

Manuscript received: 10.01 .2020 